\title{
Norsk Arkeologisk Selskaps tur til Bayern 18.-22. mai 2017
}

\section{8. mai}

62 NAS-medlemmer anført av preses Lyder Marstrander, generalsekretær Frode Iversen og styremedlem og turansvarlig Sonja V. Robøle gikk om bord i SAS' formiddagsfly til München, som var start- og endepunkt for Selskapets vårtur viet Bayern. På flyplassen i München ble vi møtt av arkeologen Michaela Helmbrecht, vår svensktalende guide som fulgte oss på hele turen.

Etter lunsj i Freising i behagelig vårvær gikk turen til første stopp i programmet, Manching, hvor vi fikk se restene av et befestet keltisk oppidum hvis navn er ukjent. Det strakte seg over 3800 mål og var bebodd fra ca. år 250 til ca. 50 f.Kr. (La Tène-perioden), og hadde 10000 innbyggere på det meste. Oppidumet kontrollerte viktige handelsruter som den handelsveien som gikk gjennom østporten og vestporten (som lå $3 \mathrm{~km}$ fra hverandre), og ble fraflyttet uten å ha blitt erobret av romerne.

Neste stopp var Castel Abusina ved Eining, et romersk såkalt auxilliarkastell ved Donau, som var i bruk fra ca. 80 e.Kr. til ut på 400-tallet (figur 1). Det huset en kohorte på opptil 600 mann på det meste. Det vi ser i dag, er resultatet av omfattende utgravninger og restaureringer fra sent 1800- og 1900-tall, og er det best bevarte og lettest tilgjengelige kastellet i Bayern.

Fra Castel Abusina dro vi videre til Altmühl-dalen (hvor Donau rant før den tok et nytt løp for 80000 år siden gjennom det såkalte Donaudurchbruch, dannet av erosjon og sideelver). I denne dalen fins et dusin steinalderhuler som går tilbake til neandertalernes tid (figur 2). Over dalen troner på den ene siden Burg Randeck, en borg fra 11.-12. århundre, og på den andre Ludvig I av Bayerns Befreiungshalle (1842-1863) til minne om de seierrike slagene mot Napoleon i 1813-1815.

\section{9. mai}

Hele dagen var viet verdensarvbyen (2006) Regensburg, Bayerns fjerde største by og største havneby. Regensburg var en viktig romersk grenseby ved Donau (Castra Regina grunnlagt i 179 e.Kr.), som utgjorde en del av Romerrikets limes. Byen var garnisonsby for 3. legion. 


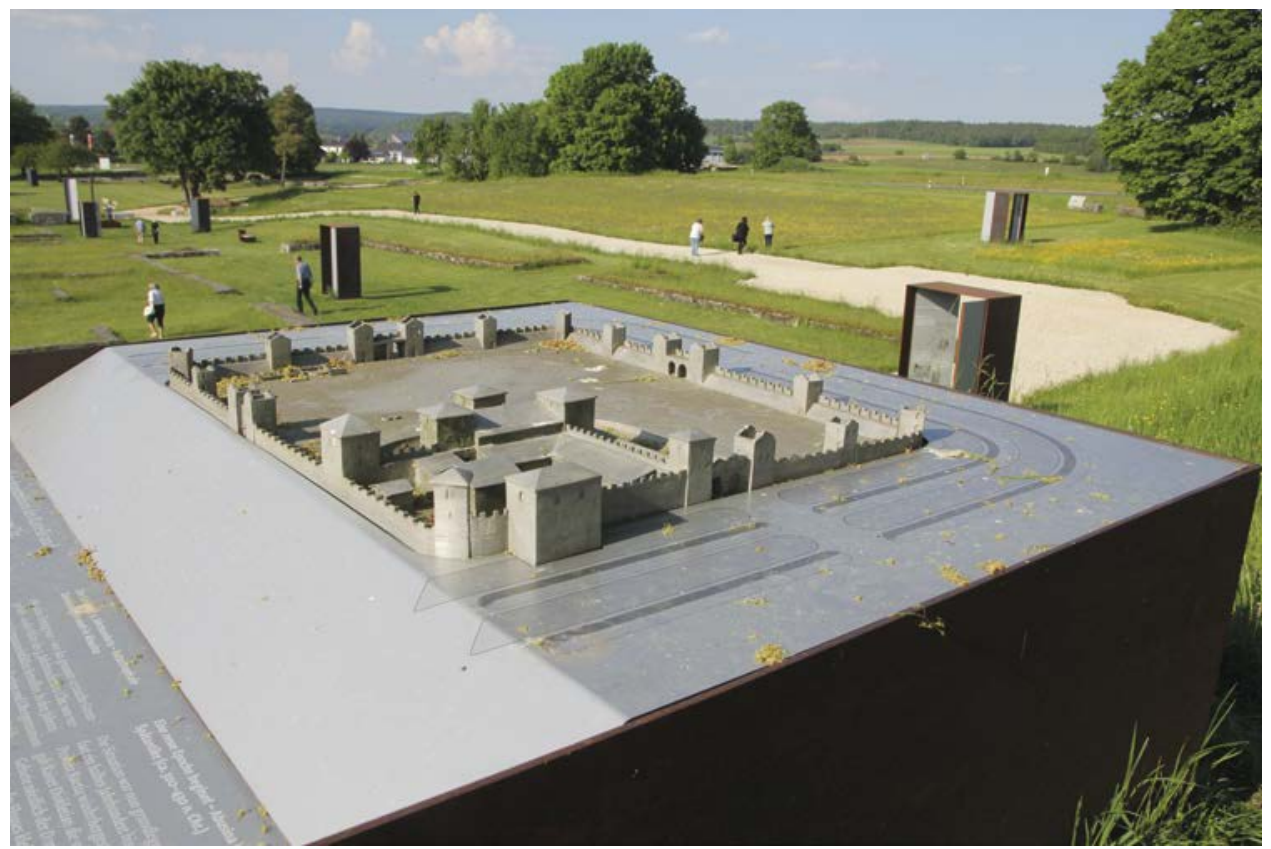

Figur 1. Modell av Castel Abusina inne i kastellområdet. Foto: Leif Dan Birkemo.

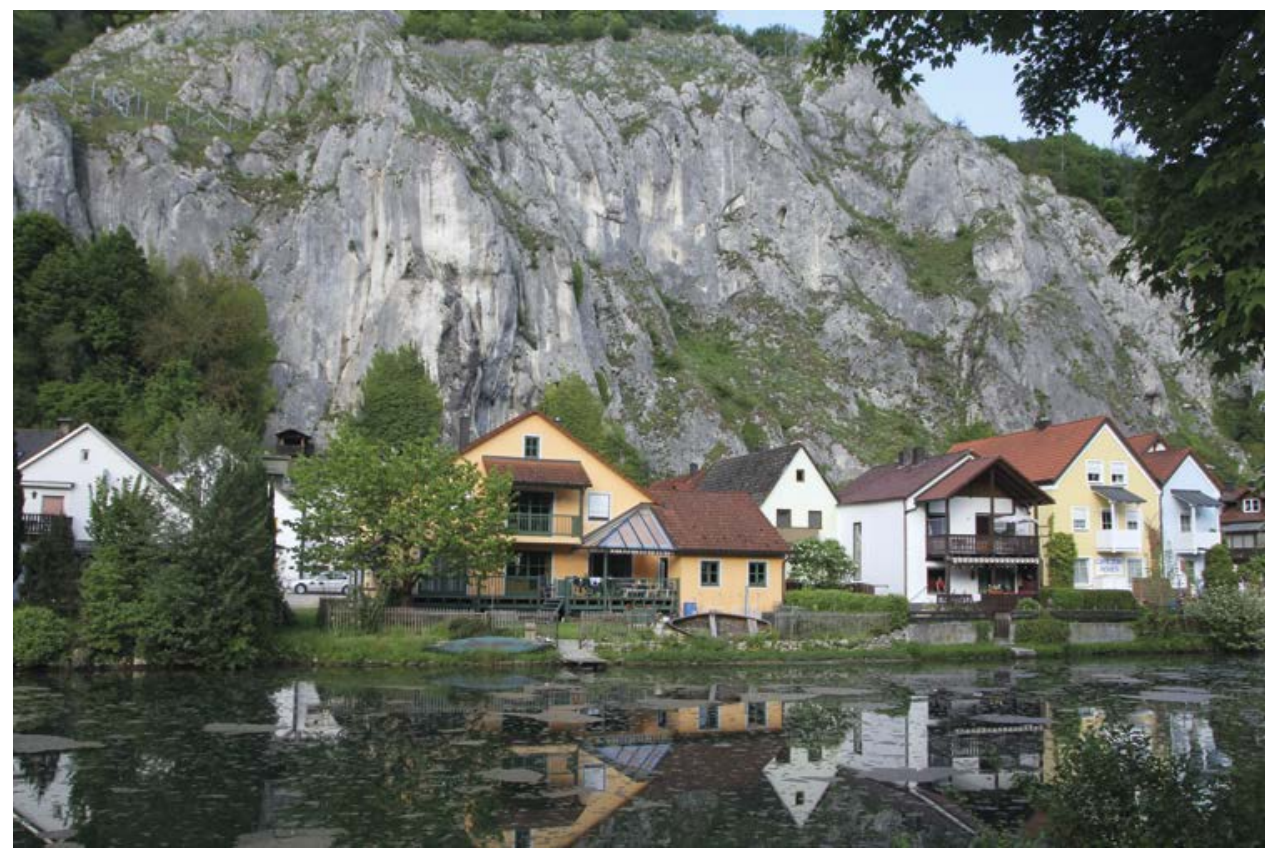

Figur 2. Altmühl-dalen med steinalderhuler ifjellet over landsbyhusene. Foto: Leif Dan Birkemo. 
Vandringen i gamlebyen, som teller 1200 fredede hus og bygninger (mange patrisierhus med italienskinspirerte tårn), var en reise i romertid og middelalder. Fra romertiden har man rester av bymuren (blant annet i et større parkeringshus) og byporter som Porta Castra Regina og Porta Praetoria (nordporten som nylig er avdekket, men ikke fullt restaurert). Fra middelalderen har man den praktfulle katedralen påbegynt i 1275, Alter Kornmarkt, rådhuset og Steinerne Brücke (1135-1146) (figur 3). Byen er stolt av å ha fostret Don Juan av Østerrike, som vant sjøslaget mot tyrkerne ved Lepanto i 1571 (statue av helten midt i gamlebyen), og bærer preg av at familien Thurn und Taxis, som representerte keiseren, har holdt hus her i et staselig slott, og gjør det fortsatt. I 1245 ble byen en fri riksstad, og fra 1663 til 1806 var den sete for den «evigvarende riksdag».

Etter lunsj besøkte vi det nylig åpnede museet Document Niedermünster, som viser hva man har gravd ut fra romertiden under benediktinernes gamle nonnekloster, som også var en utdanningsanstalt for adelige piker og unge kvinner. Museet er svært pedagogisk lagt opp, og gir et godt innblikk i hvordan legionsbyen var. Dagen ble avsluttet med et besøk i det karolingiske klosteret (som adlød bare paven og keiseren) og dets kirke viet Sankt Emmeram, som har et praktfullt barokkinteriør. Sankt Emmeram fra Poitiers nykristnet, sammen med Sankt Erhard, byen/området på 700-tallet.

\section{0. mai}

Første post på programmet var et besøk i det arkeologiske museet i Kelheim, som har velordnede og godt presenterte samlinger av funn fra romersk, keltisk og enda eldre tid. Vi så også en rekonstruert del av muren rundt det keltiske oppidum Alkimoennis, som lå her. Det var med sine 6000 mål trolig det største i Europa. Vi fant blant annet murtypene som også var blitt brukt i Manching: murus gallicus og Pfostenschlitzmauer.

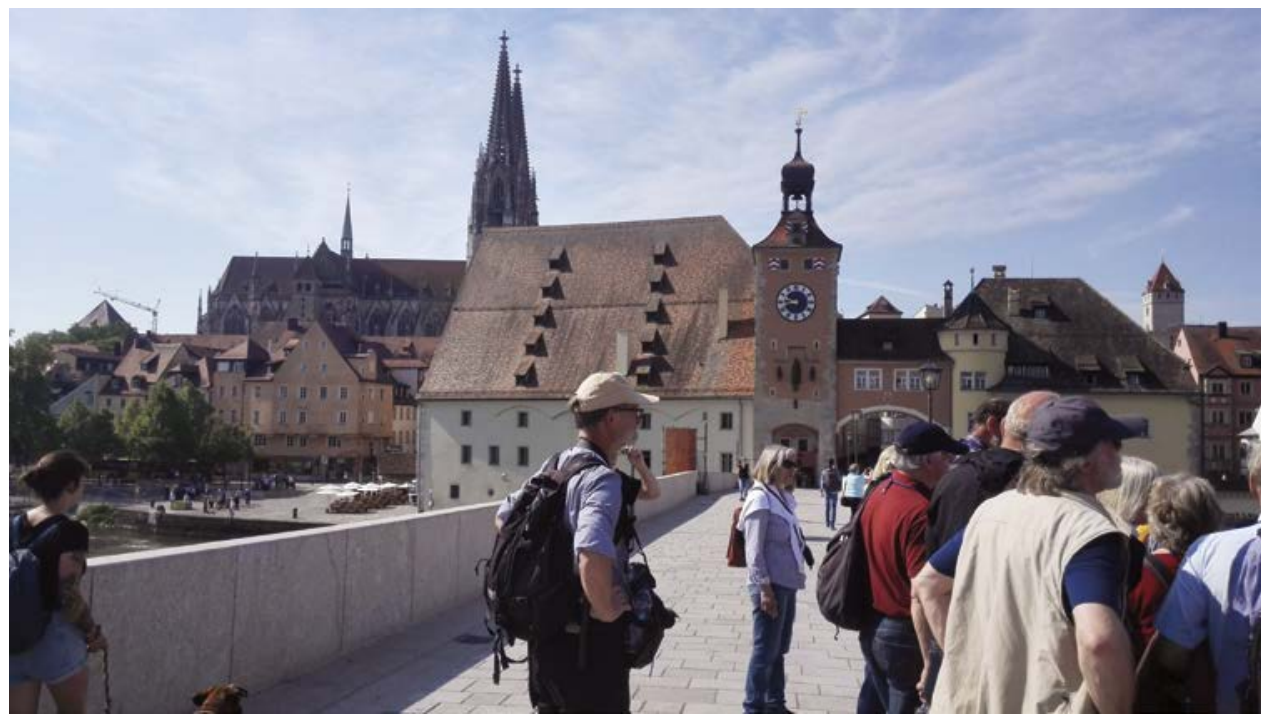

Figur 3. Steinbroen (Steinerne Brücke) over Donau i Regensburg (oppført 1135-1146), i bakgrunnen saltlageret og domkirken. Foto: Sonja Vibeche Robøle. 
Lunsjen ble inntatt i den maleriske småbyen Kallmünz, som blant annet har en Steinerne Brücke over elva Naab fra midten av 1500-tallet, flere severdige hus/bygninger fra seint 1500-tall til 1700-tallet og en kirke med et vakkert barokkinteriør. De fleste av medlemmene tok turen opp til borganlegget som ligger på en høyde rett opp fra elvas høyre bredd. Langs stien opp ligger rester av en grottebolig (trogloditt). På toppen var det forsvarsverk alt i keltisk tid, deretter var det en del av den såkalte Ungarnwall (900-tallet), mens dagens borgruin skriver seg fra første halvdel av 1300-tallet.

Turen fortsatte så mot Amberg etter en kort stopp i Ensdorf for å se en campanile fra 1075, et av Bayerns eldste byggverk. Det $21 \mathrm{~m}$ høye, hvitkalkede tårnet har tilhørt en tidligere Sankt Stefan-kirke.

I Amberg ble vi møtt av den dansktalende arkeologen dr. Mathias Hensch, som leder en av de større og viktigste utgravningene i Bayern i nyere tid, nemlig av et stort hospital (Spital) for fattige, syke og enker, grunnlagt i 1317 av Ludvig I av Bayern. Hensch hadde en grundig PowerPoint-presentasjon av prosjektet før vi ble tatt med ut og vist det store utgravningsområdet, som også omfatter hospitalets kirkegård. Den inneholder blant annet massegraver fra svartedauden (de pestdøde skiller seg ut ved å være gravlagt på magen). Ellers har man også funnet spor fra langt eldre tider som Hallstatt-perioden (800-400 f.Kr.) og kulturlag med spor etter omfattende håndverksaktivitet på 700-tallet (området hadde god tilgang på jernmalm som ble smeltet og bearbeidet).

\section{1. mai}

Dagen i Bamberg begynte med byvandring med start rett overfor det vakre, gamle rådhuset. Byen, som har 70000 innbyggere, og er bygd på sju høyder, lik Roma, har stått på UNESCOs verdensarvliste siden 1993. Den ble lite bombet under krigen, slik at det aller meste av middelalderbyen er bevart. Vi fikk blant annet et godt innblikk i byens næringsliv i gamle dager, da garvere, møllere, grønnsakdyrkere og fiskere (jf. lille Venezia) satte sitt preg på bybildet. Vandringen fortsatte opp på domkirkehøyden (Domberg) til Alte Hofhaltung (bispegårdsanlegg påbegynt på 1400-tallet), Sankt Jakobs kirke (reist mellom 1073 og 1109) og Michelsberg, hvor St. Mikaels-klosteret ligger (et benediktinerkloster grunnlagt i 1015 av Henrik II, dessverre stengt på grunn av restaurering).

Etter lunsj vandret vi fra restauranten, langs elva Regnitz som deler byen i to (venstre bredd er vernet, mens langs høyre bredd ligger det en vakker småhusbebyggelse helt ned til vannet), og videre opp på Domberg igjen. Der fikk vi en grundig omvisning utenfor og inne i katedralen, som ble påbegynt i 1002 og innviet i 1012 av senere keiser Henrik II og hans kone, Kunigunde (byens skytshelgen), som begge ligger i en praktfull marmorsarkofag laget mellom 1499 og 1513 av Tilman Riemenschneider inne i domen. To branner har ført til at dagens dom hovedsakelig er fra 1200-tallet. Det særegne er at den blant annet har fire tårn og både østkor og vestkor. I vestkoret finner man sarkofagen til pave Klemens II (10051047, pave 1046-1047), som var biskop i Bamberg. Ellers er det nok rytterstatuen Der Bamberger Reiter, en av de første som ble laget etter romertiden, som tiltrekker seg mest oppmerksomhet hos de besøkende. Ett av mange forslag er at den forestiller Sankt Stefan I av Ungarn. Etter omvisningen fikk vi litt fritid til å se oss rundt på egen hånd og eventuelt nyte et glass vin eller Rauchbier, som er byens spesialitet. 

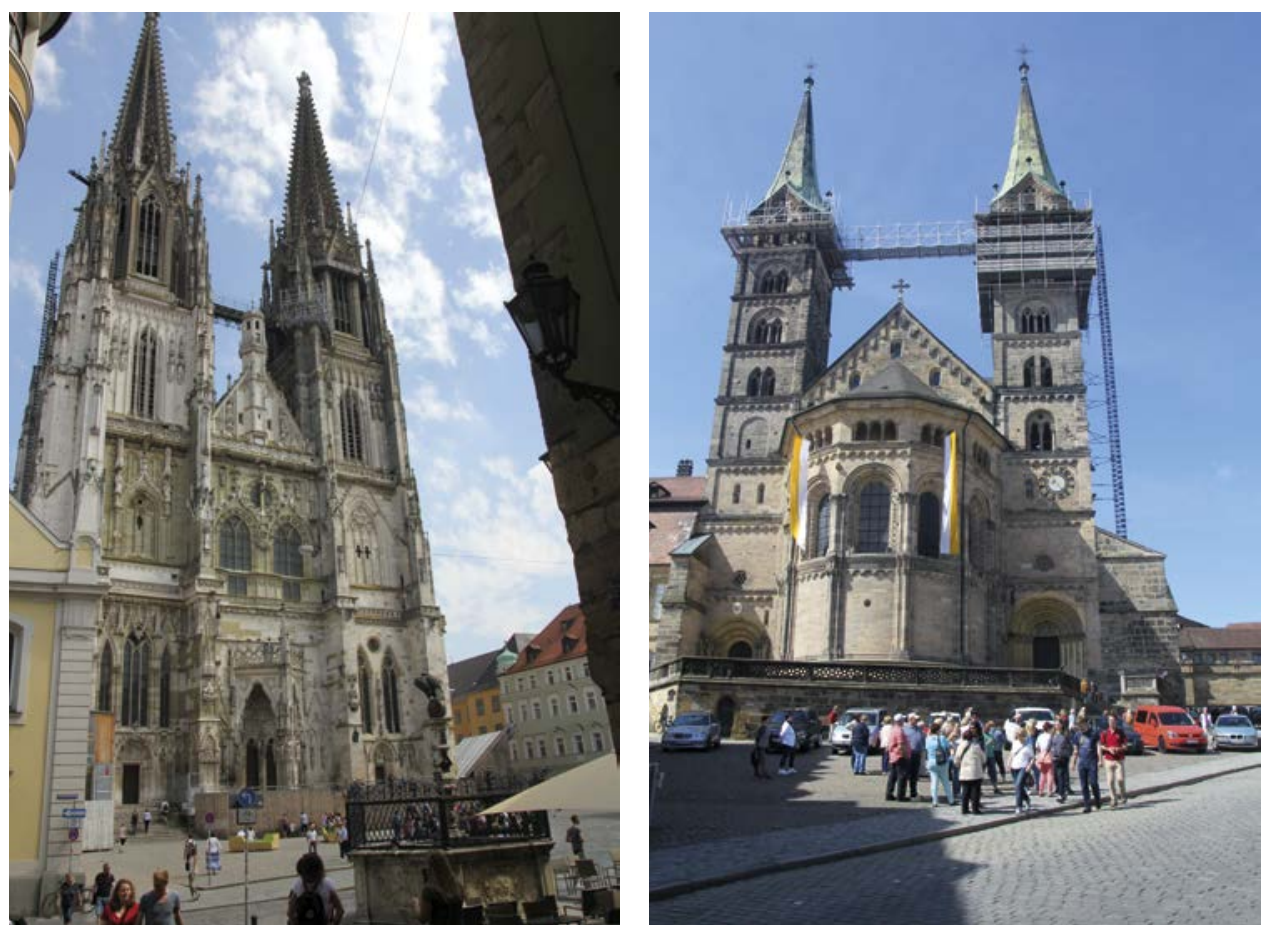

Figur 4. Regensburgdomen (til venstre) og Bambergdomen (til høyre). Foto: Leif Dan Birkemo.

\section{2. mai}

Etter frokost på våre respektive hoteller kjørte bussene oss tilbake til München. På tross av delvis saktegående trafikk på motorveien nådde vi SAS-flyet med god margin, og kunne se tilbake på en faglig svært rikholdig og interessant tur med stort sett utmerkede lokale guider. Det som var mindre vellykket, var at vi måtte bo et godt stykke utenfor både Regensburg og Bamberg og fordele oss på to hoteller fordi ingen hoteller inne $\mathrm{i}$ byene hadde plass til oss. Det førte til at det ble knapp tid til middagene inne i Regensburg og Bamberg, delvis også fordi sjåførene (som virket dårlig kjent og brukte unødvendig lang tid på å finne fram) hadde hviletider som måtte respekteres. Resultatet var at et par dårlig bemannede restauranter ikke greide å servere alle den mat og drikke som det var bestilt og betalt for. Heldigvis ble avskjedsmiddagen i den vakre restauranten på Michelsberg-høyden i Bamberg et velsmakende måltid servert innenfor en romslig tidsramme av et ustresset og tjenestevillig personale med raust påfyll av mat og vin. 
